\title{
Post-traumatic acute kidney injury: a cross-sectional study of trauma patients
}

\author{
Wei-Hung Lai ${ }^{1 \dagger}$, Cheng-Shyuan Rau ${ }^{2 \dagger}$, Shao-Chun Wu${ }^{3}$, Yi-Chun Chen ${ }^{1}$, Pao-Jen Kuo ${ }^{4}$, Shiun-Yuan Hsu', \\ Ching-Hua Hsieh ${ }^{1 *}$ and Hsiao-Yun Hsieh ${ }^{1}$
}

\begin{abstract}
Background: The causes of post-traumatic acute kidney injury (AKI) are multifactorial, and shock associated with major trauma has been proposed to result in inadequate renal perfusion and subsequent AKI in trauma patients. This study aimed to investigate the true incidence and clinical presentation of post-traumatic AKI in hospitalized adult patients and its association with shock at a Level I trauma center.

Methods: Detailed data of 78 trauma patients with AKI and 14,504 patients without AKI between January 1, 2009 and December 31, 2014 were retrieved from the Trauma Registry System. Patients with direct renal trauma were excluded from this study. Two-sided Fisher's exact or Pearson's chi-square tests were used to compare categorical data, unpaired Student's t-test was used to analyze normally distributed continuous data, and Mann-Whitney's U test was used to compare non-normally distributed data. Propensity score matching with a 1:1 ratio with logistic regression was used to evaluate the effect of shock on AKI.
\end{abstract}

Results: Patients with AKI presented with significantly older age, higher incidence rates of pre-existing comorbidities, higher odds of associated injures (subdural hematoma, intracerebral hematoma, intra-abdominal injury, and hepatic injury), and higher injury severity than patients without AKI. In addition, patients with AKI had a longer hospital stay (18.3 days vs. 9.8 days, respectively; $P<0.001$ ) and intensive care unit (ICU) stay (18.8 days vs. 8.6 days, respectively; $P<0.001)$, higher proportion of admission into the ICU (57.7\% vs. $19.0 \%$, respectively; $P<0.001)$, and a higher odds ratio (OR) of short-term mortality (OR 39.0; 95\% confidence interval, 24.59-61.82; $P<0.001$ ). However, logistic regression analysis of well-matched pairs after propensity score matching did not show a significant influence of shock on the occurrence of AKI.

Discussion: We believe that early and aggressive resuscitation, to avoid prolonged untreated shock, may help to prevent the occurrence of post-traumatic AKI. However, more evidence is required to support this observation.

Conclusion: Compared to patients without AKI, patients with AKI presented with different injury characteristics and worse outcome. However, an association between shock and post-traumatic AKI could not be identified.

Keywords: Trauma, Shock, Acute kidney injury (AKI), Mortality, Length of stay (LOS)

\section{Background}

Renal dysfunction is infrequent, but complicates both the management and the outcome of trauma patients. The incidence of post-traumatic acute kidney injury (AKI) varies widely from 0.1 to $8.4 \%$ in published series [1-7] with mortality ranging from 7 to $83 \%[1,8-11]$,

\footnotetext{
*Correspondence: m93chinghua@gmail.com

${ }^{\dagger}$ Equal contributors

'Department of Trauma Surgery, Kaohsiung Chang Gung Memorial Hospital and Chang Gung University College of Medicine, No.123, Ta-Pei Road, Niao-Song District, Kaohsiung City 833, Taiwan

Full list of author information is available at the end of the article
}

and survivors are at increased risk for chronic kidney disease and late death $[5,12-16]$. The variation is partly attributed to the controversial definition of terms such as renal insufficiency, renal dysfunction, acute renal failure, and renal failure requiring dialysis, all of which now have been substituted with the term AKI to represent the entire spectrum of acute renal failure [17-19]. However, despite technical progress in the management of AKI over the last 50 years, mortality rates of patients with AKI in critically ill patients still have remained unchanged at around 50\% [20]. 
In early literatures, AKI in trauma patients was reported to be mainly secondary to rhabdomyolysis in crush injuries [11], whereas later decreased renal perfusion was proposed as one of the most common cause of AKI [1, 21]. The shock associated with major trauma may result in inadequate renal perfusion. In addition, simultaneous changes in pro-inflammatory and antiinflammatory plasma cytokine levels in trauma patients with AKI were found [22]. These circulating factors, such as cytokines and chemokines, activated leukocytes, and adhesion molecules, may lead to distant organ immune cell infiltration and dysfunction [23]. Furthermore, AKI was demonstrated to be neutrophil-mediated during the process of ischemia-reperfusion injury [6]. Therefore, shock in major trauma may cast a detrimental effect on the kidney, which manifests in a variety of outcomes from mild azotemia to severe renal damage that requires renal replacement therapy. In this study, we aimed to investigate the true incidence and clinical presentation of post-traumatic AKI of hospitalized adult patients and its association with shock in a Level I trauma center.

\section{Methods}

\section{Study design}

This retrospective study reviewed all data added to the Trauma Registry System from January 1, 2009 through December 31, 2014 in a 2400-bed facility and Level I regional trauma center that provides care to trauma patients primarily from southern Taiwan. The coding to the Trauma Registry System spanning over these 6 years was performed by same person (Hsu SY). The inclusion criteria were all adult patients (age $\geq 20$ years) hospitalized for treatment of traumatic injury. Patients with incomplete registered data or without complete blood count test as well as blood urea nitrogen (BUN) and creatinine $(\mathrm{Cr})$ test data were excluded from the study. In this study, AKI is defined according to The Kidney Disease: Improving Global Outcomes (KDIGO) Clinical Practice Guidelines [19] as any of the following: increase in serum creatinine by $\geq 0.3 \mathrm{mg} / \mathrm{dL}$ within $48 \mathrm{~h}$; or increase in serum creatinine to $\geq 1.5$ times baseline, which is known or presumed to have occurred within the prior seven days; or urine volume $<0.5 \mathrm{~mL} / \mathrm{kg} / \mathrm{h}$ for $6 \mathrm{~h}$. Patients with acute kidney injury (AKI) were identified according to the assigned code 584.9 in ICD-9-CM for AKI, which encompasses all stages. Patients with direct trauma to the kidney or with chronic kidney disease were excluded from the study. We reviewed all 20,106 hospitalized and registered patients added to the Trauma Registry System to compare injury patterns, severity, and mortality of patients with AKI to those patients without AKI. A total of 14,504 adult patients, 78 (0.54\%) with AKI and 14,426 (99.46\%) without AKI, were enrolled in this study for further analysis. The medical records of these 78 AKI patients had been reviewed to confirm the accuracy of diagnosis and its associated information. Detailed patient information was retrieved from the Trauma Registry System of our institution, including data regarding age, sex, vital signs upon arrival at emergency department (ED), initial Glasgow Coma Scale (GCS) in the emergency department, details of procedures performed at the ED (cardiopulmonary resuscitation, intubation, chest tube insertion, and blood transfusion), Abbreviated Injury Scale (AIS) severity score for each body region, Injury Severity Score (ISS), hospital length of stay (LOS), LOS in ICU, in-hospital mortality, and rates of associated complications. Pre-existing comorbidities and chronic diseases including diabetes mellitus (DM), hypertension (HTN), coronary artery diseases (CAD), congestive heart failure (CHF), and cerebrovascular accident (CVA) were also identified. Blood alcohol concentration (BAC) of $50 \mathrm{mg} / \mathrm{dL}$ at the time of arrival to the hospital was defined as a cut-off value and the legal limit for drivers in Taiwan. If required, the doses of intravenous contrast medium Iohexol (OMNIPAQUE) for abdominal contrast-enhanced computed tomography was 60-120 cc, depending on the weight of the patient. The primary analysis was between patients with or without AKI. Odd ratios (ORs) of the associated conditions and injuries of the patients were calculated with 95\% confidence intervals (CIs). The data collected were compared using IBM SPSS Statistics for Windows, version 20.0 (IBM Corp., Armonk, NY, USA). Two-sided Fisher's exact or Pearson's chisquare tests were used to compare categorical data. Unpaired Student's t-test was used to analyze normally distributed continuous data, which was reported as mean \pm standard deviation. Mann-Whitney's U test was used to compare non-normally distributed data. To minimize confounding effects due to nonrandomized assignment in the assessment of AKI, propensity scores were calculated by using a logistic regression model and the following covariates: sex; age; comorbidity; GCS; injuries to the head/neck, thorax, abdomen, or extremities based on AIS; and ISS. A 1:1 matched study group was created by the Greedy method with NCSS software (NCSS 10, NCSS Statistical software, Kaysville, Utah). After amending these confounding factors, binary logistic regression was used in the evaluation of interventional factor of shock, which was defined as SBP $<90 \mathrm{mmHg}$, on the occurrence of AKI. $P$-values $<0.05$ were considered statistically significant.

\section{Results}

\section{Characteristics of patients with AKI}

The mean age of patients with AKI and patients without AKI were $62.9 \pm 21.0$ and $52.7 \pm 19.2$ years, respectively (Table 1). A statistically significant predominance in the percentage of men was found in patients with AKI; of the total 78 patients with AKI, 56 (71.8\%) were men and 
Table 1 Demographics and injury characteristics of the adult trauma patients with AKI

\begin{tabular}{|c|c|c|c|c|}
\hline Variables & $\begin{array}{l}\text { AKI } \\
n=78\end{array}$ & $\begin{array}{l}\text { Non-AKI } \\
n=14426\end{array}$ & $\begin{array}{l}\text { Odds ratio } \\
\text { (95\%) }\end{array}$ & $P$ \\
\hline \multicolumn{5}{|l|}{ Gender } \\
\hline Male & $56(71.8)$ & 8267 (57.3) & $1.9(1.16-3.11)$ & 0.010 \\
\hline Female & $22(28.2)$ & $6159(42.7)$ & $0.5(0.32-0.86)$ & 0.010 \\
\hline Age & $62.9 \pm 21.0$ & $52.7 \pm 19.2$ & - & $<0.001$ \\
\hline \multicolumn{5}{|l|}{ Comorbidity } \\
\hline DM & $20(25.6)$ & $2087(14.5)$ & $2.0(1.22-3.40)$ & 0.005 \\
\hline HTN & $36(46.2)$ & $3928(27.2)$ & $2.3(1.47-3.58)$ & $<0.001$ \\
\hline$C A D$ & $9(11.5)$ & $494(3.4)$ & $3.7(1.83-7.41)$ & 0.001 \\
\hline CVA & $7(9.0)$ & 569 (3.9) & $2.4(1.10-5.24)$ & 0.035 \\
\hline Alcohol >50, n (\%) & $4(5.1)$ & $989(6.9)$ & $0.7(0.27-2.01)$ & 0.547 \\
\hline GCS & $11.5 \pm 4.8$ & $14.3 \pm 2.3$ & - & $<0.001$ \\
\hline$\leq 8$ & $20(25.6)$ & $718(5.0)$ & $6.6(3.94-11.00)$ & $<0.001$ \\
\hline $9-12$ & $8(10.3)$ & $557(3.9)$ & $2.8(1.36-5.94)$ & 0.011 \\
\hline$\geq 13$ & $50(64.1)$ & $13151(91.2)$ & $0.2(0.11-0.28)$ & $<0.001$ \\
\hline \multicolumn{5}{|l|}{ AIS, n (\%) } \\
\hline Head/Neck & $35(44.9)$ & $3766(26.1)$ & $2.3(1.47-3.61)$ & $<0.001$ \\
\hline Face & $11(14.1)$ & $2158(15.0)$ & $0.9(0.49-1.77)$ & 0.832 \\
\hline Thorax & $17(21.8)$ & $1610(11.2)$ & $2.2(1.29-3.81)$ & 0.003 \\
\hline Abdomen & $11(14.1)$ & $851(5.9)$ & $2.6(1.38-4.97)$ & 0.006 \\
\hline Extremity & $41(52.6)$ & $10792(74.8)$ & $0.4(0.24-0.58)$ & $<0.001$ \\
\hline ISS & $19.8 \pm 17.3$ & $8.9 \pm 7.2$ & - & $<0.001$ \\
\hline$<16$ & $40(51.3)$ & $12119(84.0)$ & $0.2(0.13-0.31)$ & $<0.001$ \\
\hline $16-24$ & 15 (19.2) & 1599 (11.1) & $1.9(1.09-3.36)$ & 0.023 \\
\hline$\geq 25$ & $23(29.5)$ & $708(4.9)$ & $8.1(4.95-13.26)$ & $<0.001$ \\
\hline Mortality, n (\%) & 35 (44.9) & $295(2.0)$ & $39.0(24.6-61.8)$ & $<0.001$ \\
\hline LOS (days) & $18.3 \pm 16.8$ & $9.8 \pm 10.4$ & - & $<0.001$ \\
\hline \multicolumn{5}{|l|}{ ICU } \\
\hline Patients, n (\%) & $45(57.7)$ & 2744 (19.0) & $5.8(3.70-9.12)$ & $<0.001$ \\
\hline LOS in ICU (days) & $18.8 \pm 19.7$ & $8.6 \pm 11.5$ & - & 0.001 \\
\hline
\end{tabular}

$22(28.2 \%)$ were women. Significantly higher incidence rates of pre-existing comorbidities and chronic diseases including $\mathrm{DM}$ (OR, 2.0; 95\% CI, 1.22-3.40; $P=0.005)$, HTN (OR, 2.3; 95\% CI, 1.47-3.58; $P<0.001$ ), CAD (OR, 3.7; 95\% CI, 1.83-7.41; $P=0.001$ ), and CVA (OR, 2.4; 95\% CI, 1.10-5.24; $P=0.035$ ) were found among patients with AKI than among patients without AKI. There was no significant difference of positive BAC between patients with and without AKI.

Injury severity and outcome among patients with AKI

GCS scores were significantly lower in patients with AKI than in patients without AKI $(11.5 \pm 4.8$ vs. $14.3 \pm 2.3$; $P<0.001)$. There were significantly more patients with AKI that had a GCS $\leq 8$ and GCS of 9-12 compared to those of patients without AKI. Analysis of AIS revealed that patients with AKI had sustained significantly higher rates of head/neck injury, thoracic injury, and abdomen injury than patients without AKI, while patients without AKI had sustained significantly higher rates of extremity injury. A significantly higher ISS was found in patients with AKI than patients without AKI $(19.8 \pm 17.3$ vs. $8.9 \pm 7.2$, respectively; $P<0.001)$. When stratified by ISS $(<16,16-24$ or $\geq 25$ ), fewer patients with AKI had an ISS of $<16$ than patients without AKI did. In contrast, more patients with AKI had had an ISS of 16-24 or an ISS $\geq 25$ than patients without AKI. Patients with AKI had a significantly higher mortality than patients without AKI (OR, 39.0; 95\% CI, 24.69-61.8; $P<0.001)$. In addition, patients with AKI had significantly longer hospital LOS than patients without AKI (18.3 days vs. 9.8 days, respectively; $P<0.001$ ). A higher proportion of patients with AKI than patients without AKI were admitted to the ICU (57.7\% vs. $19.0 \%$, respectively; $P<0.001$ ), and the LOS in the ICU was greater for patients with AKI compared to patients without AKI (18.8 days vs. 8.6 days, respectively; $P=0.001$ ). Of the 2789 trauma patients who were admitted into the ICU during this 6-year span of study, $45(2.1 \%)$ patients had sustained AKI. In this study, 3 of 78 (3.8\%) patients with AKI required a renal replacement therapy during the hospitalization.

\section{Physiological response and procedures performed in the emergency room}

As shown in Table 2, patients with AKI exhibited higher ORs for presenting to the emergency room with worse measures of consciousness level (OR, 5.8; 95\% CI, 3.62-9.21; $P<0.001)$, systolic blood pressure (OR, 3.5; 95\% CI, 1.53-8.19; $P=0.010$ ), heart rate (OR 2.4; 95\% CI, 1.52-3.85; $P<0.001$ ), and respiratory rate (OR, 9.6; 95\% $C I, 3.42-26.80 ; P=0.001$ ) in comparison with patients without AKI. Significantly lower hemoglobin $(\mathrm{Hb})$ and hematocrit (Hct) levels, as well as higher BUN $(28.9 \pm 24.5$ vs. $15.5 \pm 10.0 ; P<0.001)$ and $\mathrm{Cr}$ $(2.1 \pm 2.2$ vs. $1.1 \pm 1.8 ; P<0.001)$ of the blood was found in patients with AKI than patients without AKI. In addition, patients with AKI had higher odds of requiring procedures, including cardiopulmonary resuscitation, intubation, chest tube insertion, and blood transfusion, in the emergency department than patients without AKI. There was no difference of SBP measured just before leaving ER $(143.9 \pm 41.1$ vs. $140.0 \pm 27.1 ; p=0.402)$ and of the time spent at ER in the patients with AKI and without AKI $(4.5 \pm 4.7$ vs. $4.2 \pm 4.7 ; p=0.566)$, albeit the exact time of a profound shock at the ER was unknown.

\section{Associated injuries among patients with AKI}

Additional file 1: Table S1 shows the incidence of associated injuries in patients with and without AKI. A 
Table 2 Significant associated injuries among the trauma patients with AK

\begin{tabular}{|c|c|c|c|c|}
\hline Variables & $\begin{array}{l}\text { AKI } \\
n=78\end{array}$ & $\begin{array}{l}\text { Non-AKI } \\
n=14426\end{array}$ & $\begin{array}{l}\text { Odds ratio } \\
(95 \%)\end{array}$ & $P$ \\
\hline \multicolumn{5}{|l|}{ Physiology at ER, n (\%) } \\
\hline GCS $<13$ & $28(35.9)$ & $1275(8.8)$ & $5.8(3.62-9.21)$ & $<0.001$ \\
\hline $\mathrm{SBP}<90 \mathrm{mmHg}$ & $6(7.7)$ & $332(2.3)$ & $3.5(1.53-8.19)$ & 0.010 \\
\hline Heart rate $>100$ beats/min & $28(35.9)$ & $2714(18.8)$ & $2.4(1.52-3.85)$ & $<0.001$ \\
\hline Respiratory rate $<10$ or $>29$ & $4(5.1)$ & $81(0.6)$ & $9.6(3.42-26.80)$ & 0.001 \\
\hline Hemoglobin ( $\mathrm{Hb})$ & $12.1 \pm 2.9$ & $13.2 \pm 2.1$ & - & 0.001 \\
\hline Hematocrit (Hct) & $35.8 \pm 7.9$ & $39.1 \pm 5.6$ & - & $<0.001$ \\
\hline BUN & $28.9 \pm 24.5$ & $15.5 \pm 10.0$ & - & $<0.001$ \\
\hline Creatinine $(\mathrm{Cr})$ & $2.1 \pm 2.2$ & $1.1 \pm 1.8$ & - & $<0.001$ \\
\hline \multicolumn{5}{|l|}{ Procedures at ER, n (\%) } \\
\hline Cardiopulmonary resuscitation & $4(5.1)$ & $21(0.1)$ & $37.1(12.42-110.66)$ & $<0.001$ \\
\hline Intubation & $12(15.4)$ & $368(2.6)$ & $6.9(3.72-12.96)$ & $<0.001$ \\
\hline Chest tube insertion & $4(5.1)$ & $184(1.3)$ & $4.2(1.51-11.56)$ & 0.019 \\
\hline Blood transfusion & $13(16.7)$ & $528(3.7)$ & $5.3(2.88-9.61)$ & $<0.001$ \\
\hline SBP before leaving ER (mmHg) & $143.9 \pm 41.1$ & $140.0 \pm 27.1$ & - & 0.402 \\
\hline Time stayed in ER (hour) & $4.5 \pm 4.7$ & $4.2 \pm 4.7$ & - & 0.566 \\
\hline
\end{tabular}

significantly higher percentage of patients with AKI had sustained subdural hematoma (OR, 1.8; 95\% CI, $1.00-3.32 ; P=0.045)$, intracerebral hematoma (OR, 3.8; 95\% CI, 1.66-8.91; $P=0.007)$, intra-abdominal injury (OR, 4.3; 95\% CI, 1.72-10.75; $P=0.008)$, hepatic injury (OR, 3.3; 95\% CI, 1.18-9.00; $P=0.040$ ), and rhabdomyolysis (OR, 183.1; 95\% CI, 68.65-488.23; $P<0.001$ ) (Table 3).

\section{Association of shock with occurrence of AKI}

After propensity score matching with a $1: 1$ ratio, 71 well-balanced pairs of patients were used for outcome comparison (Table 4). In these propensity score-matched patients, there was no significant difference in sex; age; co-morbidity (DM, HTN, CAD, and CVA); GCS; injury to head/neck, thorax, abdomen or extremities based on AIS; and ISS. Logistic regression analysis did not show that shock, under the definition of SBP $<90 \mathrm{mmHg}$, significantly influenced the occurrence of AKI (OR, 0.8; 95\% CI, 0.24-2.82; $P=0.754)$.

\section{Discussion}

This study compared the characteristics of injuries and outcome observed in a broad group of trauma patients with AKI to those of patients without AKI hospitalized at a Level I trauma center. Patients with AKI presented with a significantly older age, higher incidence rates of pre-existing comorbidities, different bodily injury patterns, and higher injury severity than patients without AKI. In addition, patients with AKI had longer hospital and ICU stays, higher proportion of admission into the ICU, and higher short-term mortality. However, logistic regression analysis of well-matched pairs after propensity score matching did not show a significant influence of shock on the occurrence of AKI.

In a multi-center cohort study of 1044 trauma patients in the ICU, renal failure developed in $3.5 \%$ of patients within $24 \mathrm{~h}$ [24]. In a large multinational, multicenter observational study involving over 29,000 critically ill patients, the prevalence of AKI was 5.7\% [2]. Post-

Table 3 Physiological response and procedures performed upon arrival at the emergency department

\begin{tabular}{lllll}
\hline Variables & $\begin{array}{l}\text { AKI } \\
n=78\end{array}$ & $\begin{array}{l}\text { Non-AKI } \\
n=14426\end{array}$ & $\begin{array}{l}\text { Odds ratio } \\
(95 \%)\end{array}$ \\
\hline Subdural hematoma (SDH) & $13(16.7)$ & $1424(9.9)$ & $1.8(1.00-3.32)$ & $3.8(1.66-8.91)$ \\
Intracerebral hematoma $(\mathrm{ICH})$ & $6(7.7)$ & $306(2.1)$ & $4.3(1.72-10.75)$ & 0.045 \\
Intra-abdominal injury & $5(6.4)$ & $226(1.6)$ & $3.3(1.18-9.00)$ & 0.007 \\
Hepatic injury & $4(5.1)$ & $235(1.6)$ & $183.1(68.65-488.23)$ & 0.040 \\
Rhabdomyolysis & $8(10.3)$ & $9(0.1)$ & & $<0.001$ \\
\hline
\end{tabular}


Table 4 Significant covariates of the trauma patients with and without AKI before and after propensity score matching (1:1 greedy matching)

\begin{tabular}{|c|c|c|c|c|c|c|c|c|}
\hline \multirow[b]{2}{*}{ Variables } & \multicolumn{4}{|c|}{ Before matching } & \multicolumn{4}{|c|}{ After matching } \\
\hline & $\begin{array}{l}\text { AKI } \\
n=78\end{array}$ & $\begin{array}{l}\text { Non-AKI } \\
n=14426\end{array}$ & $\begin{array}{l}\text { Odds ratio } \\
(95 \%)\end{array}$ & $P$ & $\begin{array}{l}\text { AKI } \\
n=71\end{array}$ & $\begin{array}{l}\text { Non-AKI } \\
n=71\end{array}$ & $\begin{array}{l}\text { Odds ratio } \\
(95 \%)\end{array}$ & $P$ \\
\hline \multicolumn{9}{|l|}{ Gender } \\
\hline Male & $56(71.8)$ & 8267 (57.3) & $1.9(1.16-3.11)$ & 0.010 & $51(71.8)$ & $51(71.8)$ & $1.0(0.48-2.08)$ & 1.000 \\
\hline Female & $22(28.2)$ & $6159(42.7)$ & $0.5(0.32-0.86)$ & 0.010 & $20(28.2)$ & $20(28.2)$ & & \\
\hline Age & $62.9 \pm 21.0$ & $52.7 \pm 19.2$ & - & $<0.001$ & $62.9 \pm 21.4$ & $62.3 \pm 21.4$ & - & 0.869 \\
\hline \multicolumn{9}{|l|}{ Comorbidity } \\
\hline DM & $20(25.6)$ & $2087(14.5)$ & $2.0(1.22-3.40)$ & 0.005 & $18(25.4)$ & $18(25.4)$ & $1.0(0.47-2.13)$ & 1.000 \\
\hline HTN & $36(46.2)$ & 3928 (27.2) & $2.3(1.47-3.58)$ & $<0.001$ & $31(43.7)$ & $31(43.7)$ & $1.0(0.52-1.94)$ & 1.000 \\
\hline$C A D$ & $9(11.5)$ & $494(3.4)$ & $3.7(1.83-7.41)$ & 0.001 & $7(9.9)$ & $7(9.9)$ & $1.0(0.33-3.02)$ & 1.000 \\
\hline CVA & $7(9.0)$ & 569 (3.9) & $2.4(1.10-5.24)$ & 0.035 & $5(7.0)$ & $5(7.0)$ & $1.0(0.28-3.62)$ & 1.000 \\
\hline GCS & $11.5 \pm 4.8$ & $14.3 \pm 2.3$ & - & $<0.001$ & $11.9 \pm 4.6$ & $12.1 \pm 4.6$ & - & 0.784 \\
\hline \multicolumn{9}{|l|}{ AIS, n (\%) } \\
\hline Head/Neck & 35 (44.9) & 3766 (26.1) & $2.3(1.47-3.61)$ & $<0.001$ & $34(47.9)$ & $34(47.9)$ & $1.0(0.52-1.93)$ & 1.000 \\
\hline Thorax & $17(21.8)$ & $1610(11.2)$ & $2.2(1.29-3.81)$ & 0.003 & 14 (19.7) & 14 (19.7) & $1.0(0.44-2.29)$ & 1.000 \\
\hline Abdomen & $11(14.1)$ & $851(5.9)$ & $2.6(1.38-4.97)$ & 0.006 & $10(14.1)$ & $10(14.1)$ & $1.0(0.39-2.57)$ & 1.000 \\
\hline Extremity & $41(52.6)$ & $10792(74.8)$ & $0.4(0.24-0.58)$ & $<0.001$ & $40(56.3)$ & $40(56.3)$ & $1.0(0.52-1.94)$ & 1.000 \\
\hline ISS & $19.8 \pm 17.3$ & $8.9 \pm 7.2$ & - & $<0.001$ & $18.3 \pm 15.2$ & $18.1 \pm 15.2$ & - & 0.960 \\
\hline $\mathrm{SBP}<90 \mathrm{mmHg}$ & $6(7.7)$ & $332(2.3)$ & $3.5(1.53-8.19)$ & 0.010 & $5(7.0)$ & $6(8.5)$ & $0.8(0.24-2.82)$ & 0.754 \\
\hline
\end{tabular}

traumatic renal failure was reported to develop in 323 (1\%) of 33,376 trauma patients, with an overall mortality of $38 \%(n=120)$ [9]. In this study, the incidence of AKI was $78(0.54 \%)$ of 14,504 hospitalized adult patients, and $45(2.1 \%)$ of 2789 patients in the ICU had sustained AKI. It has been reported that approximately one third of patients with posttraumatic AKI may be a result of inadequate resuscitation [1] and that the prognosis of posttraumatic AKI is adversely influenced by hypotension [25]. However, we did not identify a significant association of shock on the occurrence of AKI in the analysis of wellmatched pairs. The causes of post-traumatic renal failure are multifactorial [10, 26, 27]. In addition to hypovolemia, predisposing risk factors such as diabetes and hypertension, pre-existing renal impairment, sepsis, and nephrotoxins, such as aminoglycoside antibiotics and radiological contrast agents, contribute to AKI $[9,26]$. In addition, patients sustained renal failure because of prolonged untreated shock and aggressive resuscitation is recommended for such patients [25]. During recent decades, the dramatic increase in intravenous fluid administration to trauma patients during the first $24 \mathrm{~h}$ after injury has markedly reduced the incidence of AKI and has improved the outcome [28]. The change in volume therapy helped to nearly eliminate AKI from 8.4 to $3.7 \%$ [28]. The reduction of the time under a profound shock may be the key to prevent the occurrence of AKI in a trauma injury. In addition to adequate hydration of major trauma patients with shock, we believe that early identification of patients requiring resuscitation in our hospital $[29,30]$ and a shorter transport time from the injury scene [31] also might contribute to minimize complications such as AKI. However, the various trauma patient populations and injury severity as well as different indications for hospitalization and admission into the ICU make further comparison impossible. Furthermore, the exclusion of renal trauma patients from this study may reduce the incidence of AKI, albeit subsequent various outcomes depend on the various degrees and types of injury [9].

In this study, patients with AKI had sustained significantly higher rates of head/neck injury, thoracic injury, and abdomen injury, but lower rates of extremity injury than patients without AKI. In addition, a significantly higher percentage of patients with AKI had sustained subdural hematoma, intracerebral hematoma, intra-abdominal injury, and hepatic injury. There is increasing evidence in the relationship between abnormal kidney function and spontaneous intracerebral hemorrhage [32]. The use of antihypertensive agents [33] and principle of volume depletion as fluid restriction [34] had been applied in treating the patients with traumatic brain injury. In addition, it has been reported that an aggressive systolic blood pressure reduction in patients with intracerebral hemorrhage may precipitate acute renal injury [34]. However, the mechanism behind the association of post-traumatic AKI and subdural hematoma or intracerebral hematoma is unknown and yet 
to be determined. Furthermore, it has been reported that elevated intra-abdominal pressure during trauma is also a significant determinant for the impairment of renal function by direct renal compression and is not related to cardiac output [35]. An association of AKI and hepatic injury was identified in this study. Although the pathophysiological mechanisms underlying AKI in hepatic injury is unknown, it has been reported that AKI is associated with liver ischemia/reperfusion injury, which would evoke substantial systemic inflammatory responses and subsequent distant organ injury, such as to the kidney [36, 37]. Furthermore, independent predictors of mortality in patients with AKI included the severity of cardiovascular, hepatic, and neurologic dysfunction, highlighting the critical interaction between the kidney and remote organ systems [38]. In addition, although rhabdomyolysis is a recognized complication of traumatic injury to be associated with the development of AKI $[39,40]$, in this study, only 8 of 78 patients with AKI had a rhabdomyolysis. Therefore, rhabdomyolysis may only explain the development of AKI in only a few proportion of patients with AKI.

There are some limitations in this study. This retrospective design with its inherent selection bias results in a major limitation of the current study and makes it impossible to fully account for potential confounders of important risk factors. This includes a history of kidney disease other than CKD, contrast-induced nephropathy, rhabdomyolysis, left ventricular ejection fraction, perioperative and overall blood product transfusions, initial administered fluid amount, the type and duration of use of potential nephrotoxic agents, emergency surgery, type of surgery, and most important, the duration of shock and the associated lactate and base excess level at the ED. Further, the descriptive study design prevents assessment of the effects of any particular treatment intervention, and could only rely on the assumption of uniform assessment and management of patients with or without AKI. The comparison of only the initial $\mathrm{Cr}$ level but not a serial of change of $\mathrm{Cr}$ or a measured glomerular filtration rate (GFR) level may not reflect well a dynamic renal function. The time lag before $\mathrm{Cr}$ starts to rise after tubular/glomerular injury and the dilution effect of volume resuscitation after trauma injury can lead to a selection bias and some cases of AKI might have been missed. Patients declared dead upon hospital arrival or at the accident scene were not included in the Trauma Registry Database and the outcomes that included late mortality was not analyzed, which potentially biases the assessment of mortality.

\section{Conclusion}

Patients with post-traumatic AKI presented with significantly older age, higher incidence rates of pre-existing comorbidities, different bodily injury patterns, and higher injury severity than those patients without AKI. These patients with post-traumatic AKI had longer hospital and ICU stays, higher proportion of patients admitted to the ICU, and higher mortality than those without AKI. However, an association of shock with post-traumatic AKI could not be identified.

\section{Additional file}

Additional file 1: Table S1. Associated injuries among the trauma patients with or without AKI. (DOCX $17 \mathrm{~kb}$ )

\section{Abbreviations \\ AIS: Abbreviated injury scale; AKI: Acute kidney injury; BAC: Blood alcohol concentration; BUN: Blood urea nitrogen; CAD: Coronary artery diseases; CHF: Congestive heart failure; Cls: Confidence intervals; Cr: Creatinine; CVA: Cerebrovascular accident; DM: Diabetes mellitus; ED: Emergency department; GCS: Glasgow coma scale; GFR: Glomerular filtration rate; Hb: Hemoglobin; Hct: Hematocrit; HTN: Hypertension; ICU: Intensive care unit; IRB: Institutional review board; ISS: Injury severity score; KDIGO: Kidney disease: improving global outcomes; LOS: Hospital length of stay; OR: Odds ratio}

\section{Acknowledgements}

Not applicable.

\section{Funding}

This research was supported by a grant from Chang Gung Memorial Hospital CDRPG8C0032 \& CDRPG8C0033.

\section{Availability of data and materials}

No additional data are available.

\section{Authors' contributions}

WHL wrote the manuscript; CSR analyzed the tables and response to the revision; SCW drafted the manuscript; YCC performed the statistical analyses; PJK revised the manuscript; SYH collected the data and is responsible for the integrity of registered data; $\mathrm{HYH}$ revised the English and conducted the proofreading; and $\mathrm{CHH}$ designed the study and contributed to the analysis and interpretation of data. All authors read and approved the final manuscript.

\section{Competing interests}

The authors declare that they have no competing interests.

\section{Consent for publication}

Not applicable.

\section{Ethics approval and consent to participate}

This study was pre-approved by the Institutional Review Board (IRB) of the Chang Gung Memorial Hospital (approval number 104-7811B). The need for informed consent was waived according to IRB regulations.

\section{Author details}

${ }^{1}$ Department of Trauma Surgery, Kaohsiung Chang Gung Memorial Hospital and Chang Gung University College of Medicine, No.123, Ta-Pei Road, Niao-Song District, Kaohsiung City 833, Taiwan. ${ }^{2}$ Department of Neurosurgery, Kaohsiung Chang Gung Memorial Hospital and Chang Gung University College of Medicine, Kaohsiung City, Taiwan. ${ }^{3}$ Department of Anesthesiology, Kaohsiung Chang Gung Memorial Hospital and Chang Gung University College of Medicine, Kaohsiung City, Taiwan. ${ }^{4}$ Department of Plastic and Reconstructive Surgery, Kaohsiung Chang Gung Memorial Hospital and Chang Gung University College of Medicine, Kaohsiung City, Taiwan.

Received: 24 May 2016 Accepted: 15 November 2016 Published online: 22 November 2016 


\section{References}

1. Morris Jr JA, Mucha Jr P, Ross SE, et al. Acute posttraumatic renal failure: a multicenter perspective. J Trauma. 1991;31:1584-90.

2. Uchino S, Kellum JA, Bellomo R, et al. Acute renal failure in critically il patients: a multinational, multicenter study. JAMA. 2005;294:813-8.

3. Qureshi Al, Palesch YY, Martin R, et al. Systolic blood pressure reduction and risk of acute renal injury in patients with intracerebral hemorrhage. Am J Med. 2012:125:718.e711-716.

4. Jalal DI, Chonchol M, Targher G. Disorders of hemostasis associated with chronic kidney disease. Semin Thromb Hemost. 2010;36:34-40.

5. Hoste EA, Schurgers M. Epidemiology of acute kidney injury: how big is the problem? Crit Care Med. 2008;36:S146-51.

6. Awad AS, Rouse M, Huang L, et al. Compartmentalization of neutrophils in the kidney and lung following acute ischemic kidney injury. Kidney Int. 2009;75:689-98.

7. Avila Martinez RJ, Hernandez Voth A, Marron Fernandez C, et al. Evolution and complications of chest trauma. Arch Bronconeumol. 2013;49:177-80.

8. Mehta RL, Pascual MT, Soroko S, Chertow GM. Diuretics, mortality, and nonrecovery of renal function in acute renal failure. JAMA. 2002;288:2547-53.

9. Brown CV, Dubose JJ, Hadjizacharia P, et al. Natural history and outcomes of renal failure after trauma. J Am Coll Surg. 2008;206:426-31.

10. Guly UM, Turney JH. Post-traumatic acute renal failure, 1956-1988. Clin Nephrol. 1990;34:79-83.

11. Letteri JM. Post traumatic acute renal failure. Adv Exp Med Biol. 1987;212:211-8

12. Gallagher M, Cass A, Bellomo R, et al. Long-term survival and dialysis dependency following acute kidney injury in intensive care: extended follow-up of a randomized controlled trial. PLoS Med. 2014;11:e1001601.

13. Brinkman S, de Jonge $\mathrm{E}$, Abu-Hanna A, Arbous MS, de Lange DW, de Keizer NF. Mortality after hospital discharge in ICU patients. Crit Care Med. 2013:41:1229-36.

14. Thakar CV, Christianson A, Himmelfarb J, Leonard AC. Acute kidney injury episodes and chronic kidney disease risk in diabetes mellitus. Clin J Am Soc Nephrol. 2011;6:2567-72

15. Hoste EA, Clermont G, Kersten A, et al. RIFLE criteria for acute kidney injury are associated with hospital mortality in critically ill patients: a cohort analysis. Crit Care. 2006;10:R73.

16. Wohlauer MV, Sauaia A, Moore EE, Burlew CC, Banerjee A, Johnson J. Acute kidney injury and posttrauma multiple organ failure: the canary in the coal mine. J Trauma Acute Care Surg. 2012:72:373-8. discussion 379-380.

17. Bellomo R, Ronco C, Kellum JA, Mehta RL, Palevsky P. Acute renal failure definition, outcome measures, animal models, fluid therapy and information technology needs: the Second International Consensus Conference of the Acute Dialysis Quality Initiative (ADQI) Group. Crit Care. 2004:8:R204-12.

18. Levin A, Warnock DG, Mehta RL, et al. Improving outcomes from acute kidney injury: report of an initiative. Am J Kidney Dis. 2007;50:1-4.

19. National Kidney Foundation. K/DOQI clinical practice guidelines for chronic kidney disease: evaluation, classification, and stratification. Am J Kidney Dis. 2002;39:S1-S266.

20. Ympa YP, Sakr Y, Reinhart K, Vincent JL. Has mortality from acute renal failure decreased? A systematic review of the literature. Am J Med. 2005;118:827-32

21. Stene JK. Renal failure in the trauma patient. Crit Care Clin. 1990;6:111-9.

22. Bihorac A, Baslanti TO, Cuenca AG, et al. Acute kidney injury is associated with early cytokine changes after trauma. J Trauma Acute Care Surg. 2013;74:1005-13.

23. Okusa MD. The changing pattern of acute kidney injury: from one to multiple organ failure. Contrib Nephrol. 2010;165:153-8.

24. Ala-Kokko T, Ohtonen P, Laurila J, Martikainen M, Kaukoranta P. Development of renal failure during the initial $24 \mathrm{~h}$ of intensive care unit stay correlates with hospital mortality in trauma patients. Acta Anaesthesiol Scand. 2006:50:828-32.

25. Nadvi SS, Mokoena T, Gouws E, Haffejee AA. Prognosis in posttraumatic acute renal failure is adversely influenced by hypotension and hyperkalaemia. Eur J Surg. 1996;162:121-4.

26. Gettings LG, Reynolds HN, Scalea T. Outcome in post-traumatic acute renal failure when continuous renal replacement therapy is applied early vs. late. Intensive Care Med. 1999:25:805-13.

27. Rasmussen HH, Ibels LS. Acute renal failure. Multivariate analysis of causes and risk factors. Am J Med. 1982:73:211-8.
28. Regel G, Lobenhoffer P, Grotz M, Pape HC, Lehmann U, Tscherne H. Treatment results of patients with multiple trauma: an analysis of 3406 cases treated between 1972 and 1991 at a German Level I Trauma Center. J Trauma. 1995:38:70-8.

29. Chuang JF, Rau CS, Wu SC, et al. Use of the reverse shock index for identifying high-risk patients in a five-level triage system. Scand J Trauma Resusc Emerg Med. 2016;24:12.

30. Lai WH, Rau CS, Hsu SY, et al. Using the Reverse Shock Index at the Injury Scene and in the Emergency Department to Identify High-Risk Patients: A Cross-Sectional Retrospective Study. Int J Environ Res Public Health. 2016:13:E357.

31. Huang CY, Rau CS, Chuang JF, et al. Characteristics and Outcomes of Patients Injured in Road Traffic Crashes and Transported by Emergency Medical Services. Int J Environ Res Public Health. 2016;13:E236.

32. Cutting $\mathrm{S}$, Castro $\mathrm{C}$, Lee $\mathrm{VH}$, Prabhakaran $\mathrm{S}$. Impaired renal function is not associated with increased volume of intracerebral hemorrhage. J Stroke Cerebrovasc Dis. 2014;23:86-90.

33. Jivraj S, Mazer CD, Baker AJ, Choi M, Hare GM. Case report: profound hypotension associated with labetalol therapy in a patient with cerebral aneurysms and subarachnoid hemorrhage. Can J Anaesth. 2006:53:678-83.

34. Rodriguez GJ, Cordina SM, Vazquez G, et al. The hydration influence on the risk of stroke (THIRST) study. Neurocrit Care. 2009:10:187-94.

35. Harman PK, Kron IL, McLachlan HD, Freedlender AE, Nolan SP. Elevated intra-abdominal pressure and renal function. Ann Surg. 1982:196:594-7.

36. Lee SY, Kim DH, Sung SA, et al. Sphingosine-1-phosphate reduces hepatic ischaemia/reperfusion-induced acute kidney injury through attenuation of endothelial injury in mice. Nephrology (Carlton). 2011;16:163-73.

37. Pawarode A, Fine DM, Thuluvath PJ. Independent risk factors and natural history of renal dysfunction in liver transplant recipients. Liver Transpl. 2003;9:741-7.

38. Eachempati SR, Wang JC, Hydo LJ, Shou J, Barie PS. Acute renal failure in critically ill surgical patients: persistent lethality despite new modes of renal replacement therapy. J Trauma. 2007:63:987-99.

39. Elterman J, Zonies D, Stewart I, Fang R, Schreiber M. Rhabdomyolysis and acute kidney injury in the injured war fighter. J Trauma Acute Care Surg. 2015;79:S171-4.

40. Polderman $\mathrm{KH}$. Acute renal failure and rhabdomyolysis. Int J Artif Organs. 2004:27:1030-3.

\section{Submit your next manuscript to BioMed Central and we will help you at every step:}

- We accept pre-submission inquiries

- Our selector tool helps you to find the most relevant journal

- We provide round the clock customer support

- Convenient online submission

- Thorough peer review

- Inclusion in PubMed and all major indexing services

- Maximum visibility for your research

Submit your manuscript at www.biomedcentral.com/submit 